\title{
Proof-of-concept study investigating the role of S100P-RAGE in nasopharyngeal carcinoma
}

\author{
CHENGYU WANG $^{1}$, XUEQIAO WANG ${ }^{1}$, ANGXUAN HAN $^{2}$, YUHAO WANG $^{3}$ and HUI JIANG ${ }^{1}$ \\ ${ }^{1}$ Department of Otolaryngology, ${ }^{2}$ Research Center for Clinical Medicine and ${ }^{3}$ Department of Pathology, \\ Jinshan Hospital, Fudan University, Shanghai 201508, P.R. China
}

Received March 19, 2020; Accepted February 1, 2021

DOI: $10.3892 /$ etm.2021.9901

\begin{abstract}
Nasopharyngeal carcinoma (NPC) is an epithelial carcinoma that arises from the lining of the nasopharyngeal mucosa. The efficacy of radiation therapy is limited due to radiation resistance, particularly in the advanced stages of NPC. The S100P protein is a small isoform of the S100 protein family, which is involved in the regulation of various intracellular and extracellular processes, including proliferation, differentiation and intracellular signaling. The aim of the current study was to investigate the significance of the S100P-RAGE axis in NPC progression. The expression levels of S100P and receptor for activated glycation end-products (RAGE) in NPC specimens were determined by western blotting. In addition, the effect of the S100P-RAGE axis on NPC was evaluated in vitro by proliferation and migration assays using C666-1 cells treated with S100P or the RAGE inhibitor FPS-ZM1. The underlying mechanism was also investigated by western blotting. The expression of S100P and RAGE was detected in clinical specimens from 15 patients with NPC and 15 patients with benign nasopharyngeal inflammation, and was observed to be higher in NPC tissues compared with inflamed tissues. Furthermore, the interaction of S100P with RAGE increased the proliferation and migration potential of C666-1 cells, and activated mitogen-activated protein kinase and NF- $\kappa \mathrm{B}$ signaling. These results indicate that the S100P-RAGE axis exerts a promoting effect on the progression of NPC. Therefore therapeutic strategies targeting S100P-RAGE merit further exploration for the treatment of NPC.
\end{abstract}

Correspondence to: Dr Hui Jiang, Department of Otolaryngology, Jinshan Hospital, Fudan University, 1508 Longhang Road, Shanghai 201508, P.R. China

E-mail: jianghuiluck@aliyun.com

Abbreviations: NPC, nasopharyngeal carcinoma; RAGE, receptor for activated glycation end-products; MAPK, mitogen-activated protein kinase; ERK, extracellular signal-related kinase; SDS, sodium dodecyl sulfate

Key words: S100P, RAGE, proliferation, migration, C666-1 cells

\section{Introduction}

Nasopharyngeal carcinoma (NPC) is an epithelial carcinoma that arises from the lining of the nasopharyngeal mucosa (1). The tumors are usually observed at the pharyngeal recess in the nasopharynx. Despite originating from similar cell or tissue lineages, NPC is distinct from other epithelial head and neck tumors (2). NPC is characterized by poorly or undifferentiated carcinomas. It differs from other head and neck squamous cell carcinomas in several ways, including its association with the Epstein-Barr virus (EBV), increased radio- and chemosensitivity, and a greater propensity for distant metastases (3). Compared with other cancers, NPC is relatively uncommon. The incidence of NPC has a marked geographical distribution; it is most prevalent in South China, with an annual incidence of $\sim 30$ cases per 100,000 population (4). NPC is associated with multiple risk factors, including genetic susceptibility and environmental factors, such as EBV infection and dietary intake $(5,6)$.

Proteins of the S100 family are small $\mathrm{Ca}^{2+}$-binding proteins with a helix-loop-helix (EF-hand type) binding motif, and have been demonstrated to participate in the regulation of various intracellular and extracellular processes, including cell proliferation and differentiation, and intracellular signaling (7). Receptor for activated glycation end products (RAGE) is a receptor for multiple ligands that belongs to the immunoglobulin family. The dysregulation of RAGE has been indicated to be a critical step in the development and metastasis of numerous types of tumors, including head and neck cancer $(8,9)$. RAGE is able to interact with structurally diverse ligands, and although these interactions appear to involve oligomerization of the receptor on the cell surface (10), the exact mechanism is unknown. Members of the S100 protein family are known to be RAGE ligands (10). Several S100 proteins, including S100A12 and S100B, are released from cells and have the ability to activate RAGE, suggesting that this may be an important mechanism underlying the extracellular effects of S100 proteins (11). The S100P protein is a small isoform of the $\mathrm{S} 100$ protein family, the ' $\mathrm{P}$ ' in its name reflecting its original isolation from the placenta by Becker et al (12) in 1992. S100P is a 95-amino-acid protein, which is encoded by a gene located on chromosome $4 \mathrm{pl}$. S100P has been reported to interact with several proteins, both extracellularly and intracellularly, and 
its upregulation in various types of human cancer has been shown to be associated with disease progression, the acquisition of chemoresistance and poor prognosis $(13,14)$.

In our previous study, the differential expression of S100P between NPC tissues and the tissues of patients with benign inflammation was identified using immunohistochemistry, and S100P was demonstrated to be associated with proliferation and migration in the C666-1 NPC cell line (15). However, the role of RAGE activation in S100P signaling has not yet been examined in C666-1 cells and the mechanism remains unclear.

In the present study, to determine whether the activation of RAGE by S100P is required for S100P to exert its effects on cell growth and survival, the activation of RAGE by S100P was blocked and the effects on cell function and signaling were investigated using a variety of methods. Mechanisms involving the activation of extracellular signal-related kinase 1/2 (ERK1/2), mitogen-activated protein kinase 7

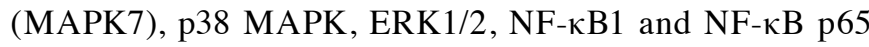
were investigated.

\section{Materials and methods}

Patients and tumor samples. In total, 30 patients were included in the study, 15 with NPC and 15 with benign nasopharyngeal inflammation. The samples were obtained from patients who were hospitalized for nasopharyngeal biopsy between April 2018 and September 2019 at the Department of Otolaryngology, Jinshan Hospital, Fudan University (Shanghai, China). The patients were diagnosed with NPC or benign nasopharyngeal inflammation through pathological examination. None of the patients had undergone chemotherapy or radiotherapy, or had any other tumors. Tissue samples were frozen immediately in liquid nitrogen and stored at $-80^{\circ} \mathrm{C}$ until used. The clinical characteristics of the patients are shown in Table I. The study cohort comprised 16 men $(53.3 \%)$ and 14 women $(46.7 \%)$ with an age range of $25-79$ years (mean age, $50.3 \pm 14.9$ years; Table I). The NPC group comprised 10 men and 5 women (mean age, $55.13 \pm 15.19$ years). The Benign nasopharyngeal inflammation group consisted of 6 men and 9 women (mean age, $45.4 \pm 13.88$ years). When the collection of tissue samples took place, the participants signed informed consent forms to confirm that they agreed to the use of their tissues in scientific research.

Cell culture and treatments. The C666-1 NPC cell line was purchased from the cell bank of the Central Laboratory of Xiangya Hospital (Central South University). The cell line was authenticated by the provider and tested for Mycoplasma contamination. The C666-1 cell line was established by Cheung et al (16) from undifferentiated NPC, and consistently carries EBV in long-term culture. The C666-1 cells were cultured in RPMI-1640 medium (Sigma-Aldrich; Merck KGaA) supplemented with $10 \%$ certified fetal bovine serum (FBS; Biological Industries) and maintained in a humidified incubator containing $5 \% \mathrm{CO}_{2}$ at $37^{\circ} \mathrm{C}$. The medium was replaced with fresh culture medium every 3-4 days. The following three groups of C666-1 cells were used in subsequent assays: The S100P protein group, treated with S100P (cat. no. Ag19115; Proteintech Group, Inc.), the
FPS-ZM1 group, treated with the RAGE inhibitor FPS-ZM1 (cat. no. 6237; Tocris Bioscience) (17), and the untreated control group. The S100P protein and RAGE inhibitor were separately dissolved in cell culture medium and prepared for immediate use.

Western blot analysis. Total proteins were extracted from the tissue samples and cells following lysis with sodium dodecyl sulfate (SDS) lysis buffer containing phenylmethanesulfonyl fluoride and proteinase inhibitor (100:1:1; Nanjing KeyGen Biotech Co., Ltd.) using an automatic grinding machine (JXFSTPRP-24; Jingxin Technology Co., Ltd.) at $50 \mathrm{~Hz}$ for $60 \mathrm{sec}$. The supernatant was collected and the protein concentration was determined using a BCA protein assay (Beyotime Institute of Biotechnology). Western blotting was performed using a standard method (18). Quantified proteins (50 $\mu \mathrm{g}$ per lane) were separated by electrophoresis using 8-12\% SDS polyacrylamide gels and electroblotted onto polyvinylidene fluoride membranes. The membranes were blocked with $5 \%$ non-fat milk in tris buffer saline containing $0.05 \%$ Tween-20 for $1 \mathrm{~h}$ at room temperature. The membranes were then incubated sequentially at $4^{\circ} \mathrm{C}$ overnight with primary antibodies. Primary antibodies targeting S100P (cat. no. 11803-1-AP; 1:1,000), RAGE (cat. no. 16346-1-AP; 1:1,000), ERK1/2 (cat. no. 66192, 1:1,000), p38 (cat. no. 66234; 1:1,000), MAPK7 (cat. no. 10036-2-AP; 1:1,000), NF-кB1 (cat. no. 14220-1-AP; 1:1,000), p65 (cat. no. 10745-1-AP; 1:1,000) and GAPDH (cat. no. 10494-1-AP; 1:5,000) were acquired from Proteintech Group, Inc. and antibodies targeting phosphorylated (p)-ERK1/2 (ab201015; 1:1,000), p-p38 (ab4822; 1:1,000) and p-MAPK7 (ab5686, 1:1,000) Abcam. Following this, the membranes were incubated with HRP-conjugated secondary antibodies (cat. no. SA00001-2; Proteintech; 1:5,000) for $1 \mathrm{~h}$ at room temperature. The resulting protein-antibody complexes were detected using an ECL system (Merck KGaA) and then visualized using AllDoc version 2.2.1.0 software with the Tanon 4500 imaging system (Tanon Science and Technology Co., Ltd.).

Cell Counting Kit-8 (CCK-8) assay. The C666-1 cells were seeded at a density of 3,000 cells/well in 96-well plates. After $24 \mathrm{~h}$, the cell viability was determined using a CCK-8 assay (Dojindo Molecular Technologies, Inc.), by measurement of the optical density at $450 \mathrm{~nm}$ (OD450) according to the kit protocol. Following this, a range of concentrations $(10,100$, $500,1,000$ and $5,000 \mathrm{ng} / \mathrm{ml}$ ) of S100P protein or FPS-ZM1 were added to the wells, an untreated control group was established, and the cells were cultured for $6 \mathrm{~h}$ at $37^{\circ} \mathrm{C}$. In subsequent experiments, the S100P protein and FPS-ZM1 were used at a concentration of $1,000 \mathrm{ng} / \mathrm{ml}$, since at this concentration, the inhibition and proliferation rates were $\sim 50 \%$, respectively. Cell viability was assessed using the CCK- 8 assay after incubation for 6,12 and $24 \mathrm{~h}$ by adding $10 \mu \mathrm{l} \mathrm{CCK}-8$ solution to each well, incubating for $30 \mathrm{~min}$ to $4 \mathrm{~h}$ at $37^{\circ} \mathrm{C}$ according to the manufacturer's protocol, after which the OD450 value was measured.

Colony formation assay. The C666-1 cells were cultured in 6-well plates at a density of 2,000 cells/well. After $24 \mathrm{~h}$, $1,000 \mathrm{ng} / \mathrm{ml} \mathrm{S100P}$ protein or FPS-ZM1 was added to each well 
Table I. Clinical characteristics of the patients.

\begin{tabular}{|c|c|c|c|}
\hline Characteristic & Total no. of patients $(n=30)$ & No. of NPC cases $(n=15)$ & No. of benign inflammation cases $(n=15)$ \\
\hline \multicolumn{4}{|l|}{ Sex } \\
\hline Male & 16 & 10 & 6 \\
\hline Female & 14 & 5 & 9 \\
\hline \multicolumn{4}{|l|}{ Age (years) } \\
\hline$<50$ & 14 & 6 & 8 \\
\hline$\geq 50$ & 16 & 9 & 7 \\
\hline \multicolumn{4}{|l|}{ Stage } \\
\hline I & & 1 & \\
\hline II & & 6 & \\
\hline III & & 6 & \\
\hline IV & & 2 & \\
\hline \multicolumn{4}{|c|}{ Histological subtype } \\
\hline Non-keratinized & & 15 & \\
\hline Undifferentiated & & 0 & \\
\hline
\end{tabular}

and the cells were cultured for a further $\sim 14$ days at $37^{\circ} \mathrm{C}$. The colonies were then stained with $0.4 \%$ crystal violet (Beyotime Institute of Biotechnology). The numbers of colonies that contained $>50$ cells were counted and averaged (19).

Wound healing assays. The C666-1 cells were cultured in 6 -well plates until they reached confluency. The monolayers were scratched and the detached cells were washed away using PBS solution. Then, $1,000 \mathrm{ng} / \mathrm{ml} \mathrm{S100P}$ protein or FPS-ZM1 was added to each well and the cells were cultured in serum-free RPMI-1640 for $24 \mathrm{~h}$ at $37^{\circ} \mathrm{C}$. The width of the wound was measured at 0 and $24 \mathrm{~h}$ with an inverted microscope equipped with a digital camera (Olympus Corporation).

Transwell migration assay. Transwell chambers (pore size, $8 \mu \mathrm{m}$; Corning Life Sciences) were used for the Transwell migration assay. A total of $2 \times 10^{5}$ cells suspended in $100 \mu \mathrm{l}$ serum-free medium with or without S100P protein or FPS-ZM1 were added to the upper chamber, and medium containing $20 \%$ FBS was added to the lower chamber. The chambers were incubated for $24 \mathrm{~h}$ at $37^{\circ} \mathrm{C}$. Subsequently, the cells that had migrated through the membrane were fixed, stained with crystal violet for $20 \mathrm{~min}$ at room temperature and counted in 5 random fields with an inverted microscope equipped with a digital camera (Olympus Corporation).

Statistical analysis. All experimental assays were conducted as at least three independent experiments. Data are expressed as the mean \pm SD. Data analysis was performed using SPSS version 26.0 (IBM Corp.). Comparison of the protein levels between the NPC and benignly inflamed tissues was performed using independent-sample t-tests. Kruskal-Wallis and Mann-Whitney U tests were used to analyze the differences in S100P expression level among or between patients according to disease stage, age and gender. Comparisons of multiple groups in other assays were performed by one-way ANOVA followed by Bonferroni post hoc tests for the multiple comparisons. $\mathrm{P}<0.05$ was considered to indicate a statistically significant difference.

\section{Results}

Protein expression of S100P and RAGE in NPC. To evaluate the levels of S100P and RAGE in nasopharyngeal tumors, the tumor samples of 15 patients with NPC and tissues of 15 patients with benign nasopharygeal inflammation were analyzed. The western blotting results revealed that S100P $(\mathrm{P}<0.001$; Fig. 1A and $\mathrm{B})$ and RAGE $(\mathrm{P}<0.05$; Fig. 1A and $\mathrm{C})$ were significantly upregulated in the NPC tissues compared with the tissues with benign inflammation. The associations of the S100P expression level with disease stage and the age and gender of the patients were also analyzed. The S100P expression level was found to differ significantly according to disease stage when analyzed using a Kruskal-Wallis test $(\mathrm{P}<0.01$; Table II); however, no significant difference in $\mathrm{S} 100 \mathrm{P}$ expression level was detected according to the age and gender of the patients when analyzed using a Kruskal-Wallis and Mann-Whitney U test (Table II).

Effects of S100P-RAGE on cell proliferation. We hypothesized that the effects of S100P in NPC might be due to its binding with RAGE and the activation of autocrine signaling mechanisms. Therefore, three groups of C666-1 cells were analyzed, namely the S100P protein group, the FPS-ZM1 group and the untreated control group. These groups were analyzed in cell viability and migration assays to identify the association between S100P and RAGE.

Different concentrations of S100P protein and the RAGE inhibitor FPS-ZM1 were added to C666-1 cells to test their effects on cell viability. The effects of S100P protein and FPS-ZM1 on cell viability were observed to be concentration-dependent $(\mathrm{P}<0.001$ and $\mathrm{P}<0.01$, respectively; Fig. $2 \mathrm{~A}$ and $\mathrm{B})$. Furthermore, the effects of S100P protein and FPS-ZM1 on cell viability were found to be time-dependent. Compared with that in the untreated control group, cell viability was significantly affected at 6 and 
Table II. Differences in S100P expression levels according to the disease stage, age and sex of patients.

\begin{tabular}{lccc}
\hline Characteristic & Number of cases $(\mathrm{n}=30)$ & Relative S100P expression & S100P expression (P-value) \\
\hline Sex & 16 & & 0.058 \\
Male & 14 & $0.327 \pm 0.179$ & \\
Female & & $0.254 \pm 0.264$ & 0.42 \\
Age (years) & 14 & & \\
$<50$ & 16 & $0.301 \pm 0.272$ & 0.017 \\
$\geq 50$ & 15 & $0.308 \pm 0.176$ & \\
Stage & 1 & $0.137 \pm 0.059$ & \\
Benign inflammation & 6 & 0.092 & 0.005 \\
I & 6 & $0.417 \pm 0.267$ & \\
II & 2 & $0.493 \pm 0.138$ & \\
III & & $0.596 \pm 0.06$ & \\
IV & & & \\
\hline
\end{tabular}

A

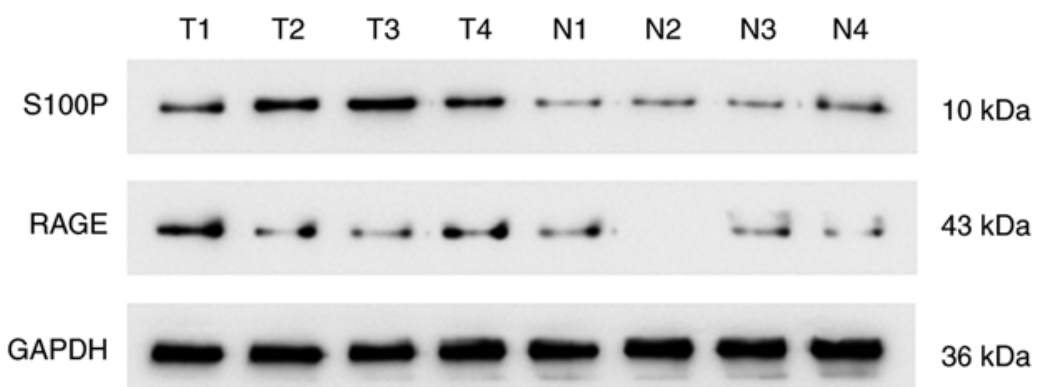

B

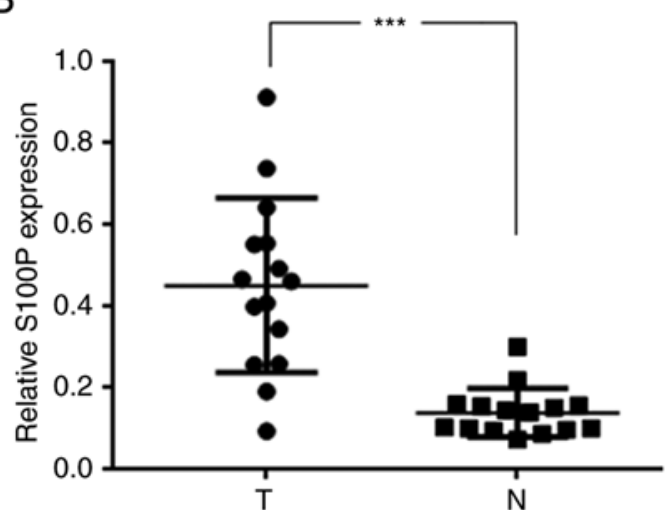

C

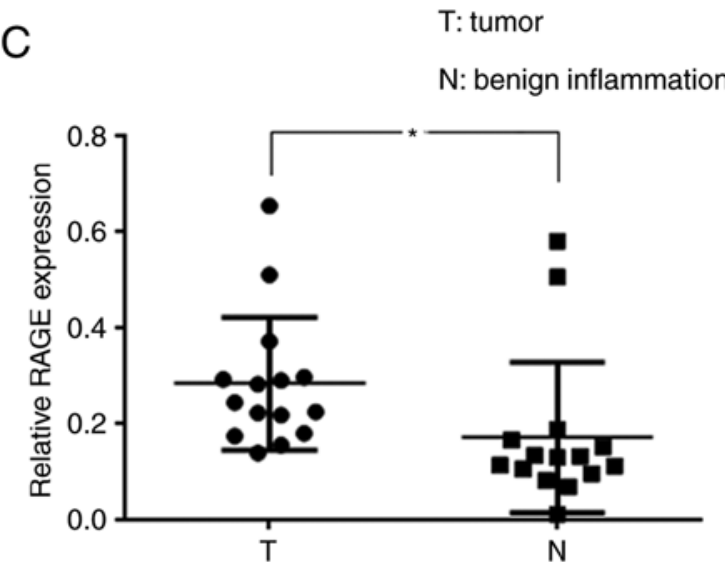

Figure 1. Protein expression of S100P and RAGE in patients with NPC or benign nasopharyngeal inflammation. (A) The protein expression of S100P and RAGE in NPC tissues and nasopharyngeal tissues with benign inflammation by western blotting. Quantification of (B) S100P/GAPDH and (C) RAGE/GAPDH protein expression ratios. ${ }^{*} \mathrm{P}<0.05$ and ${ }^{* * *} \mathrm{P}<0.001$. RAGE, receptor for activated glycation end products; NPC, nasopharyngeal carcinoma.

$12 \mathrm{~h}$ following treatment with S100P protein or FPS-ZM1 at a concentration of $1,000 \mathrm{ng} / \mathrm{ml}(\mathrm{P}<0.01$ and $\mathrm{P}<0.001$, respectively; Fig. 2C). The $1,000 \mathrm{ng} / \mathrm{ml}$ concentration was selected for use in subsequent experiments on the basis that it is the concentration at which the inhibition and proliferation rates for S100P and FPS-ZM1 are $50 \%$, respectively (data not shown). The colony forming assay revealed that the ability of C666-1 cells to form colonies was increased by treatment with S100P protein and decreased by treatment with the RAGE inhibitor FPS-ZM1 $(\mathrm{P}<0.001$; Fig. 2D and E).
Effects of S100P-RAGE on cell migration. The effects of S100P and FPS-ZM1 on the migration of C666-1 cells were assessed by wound healing and Transwell assays. As presented in Fig. 3A and B, measurements made $24 \mathrm{~h}$ following wounding of the cell monolayer revealed that wound closure was induced in the S100P protein group and delayed in FPS-ZM1 group compared with the untreated control group. The migrated distances of the cells in the untreated control group, S100P protein group and FPS-ZM1 group were 746.67 $\pm 55.28,1,139.39 \pm 77.61$ and 
A

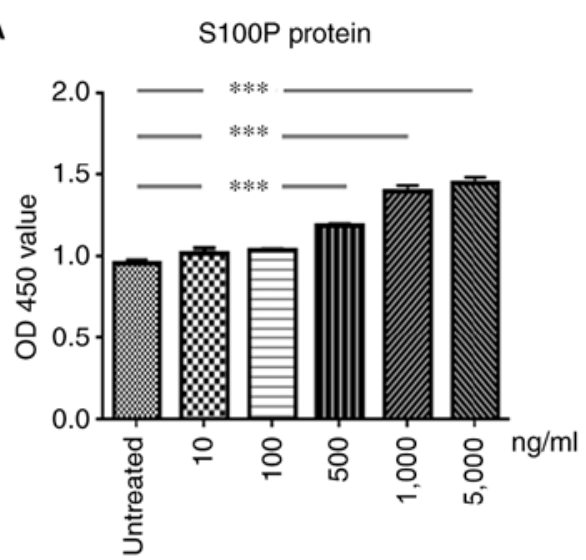

D

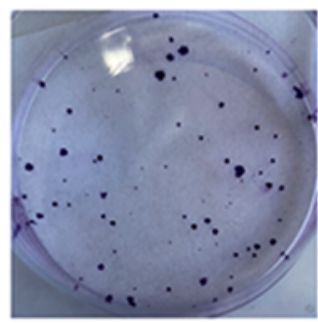

Untreated control
B
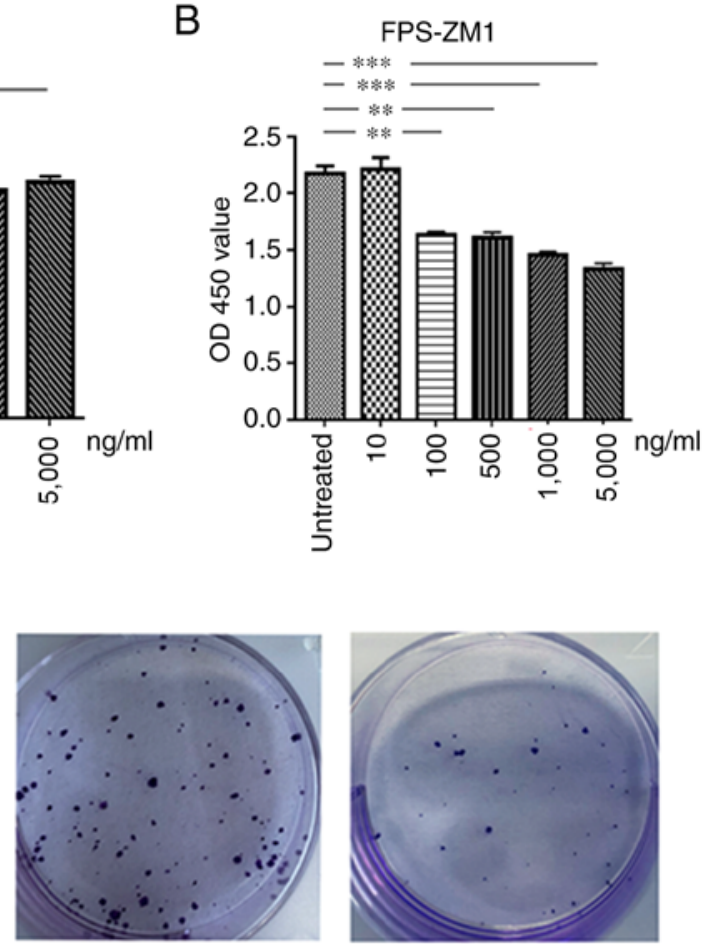

S100P protein

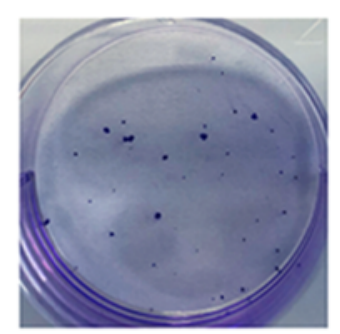

FPS-ZM1
C

- Untreated control $\leftarrow$ S100P protein - FPS-ZM1

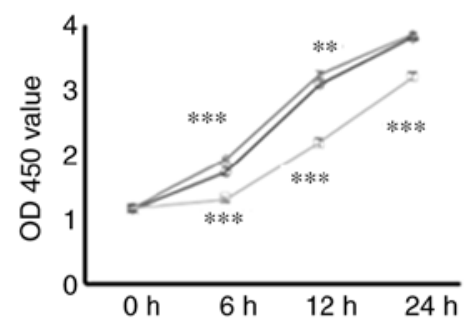

E

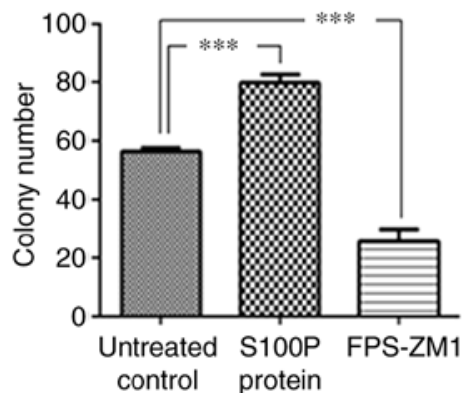

Figure 2. Effects of S100P and RAGE on the proliferation and colony formation of C666-1 cells. Cell Counting Kit-8 assay results for the growth evaluation of cells treated with (A) S100P protein or (B) RAGE inhibitor FPS-ZM1 at the indicated concentrations for $6 \mathrm{~h}$. The effects of S100P and FPS-ZM1 on cell viability were concentration-dependent. (C) The effects of S100P protein and FPS-ZM1 (both 1,000 ng/ml) on cell viability were also time-dependent. (D) Representative images of colony formation assay results. (E) The colony forming ability of C666-1 cells was increased in the S100P protein group and reduced in the FPS-ZM1 group. ${ }^{* *} \mathrm{P}<0.01$ and ${ }^{* * *} \mathrm{P}<0.001$ vs. untreated control. RAGE, receptor for activated glycation end products; OD450, optical density at $450 \mathrm{~nm}$.

$276.36 \pm 112.21 \mu \mathrm{m}$, respectively $(\mathrm{P}<0.001$; Fig. 3A and B). The percentage of wound closure in the untreated control, S100P protein and FPS-ZM1 groups was calculated to be $41.79,65.23$ and $16.17 \%$, respectively $(\mathrm{P}<0.001$; Fig. $3 \mathrm{C})$. The Transwell assay revealed that the addition of S100P protein significantly increased the migration ability of the C666-1 cells, while the addition of the RAGE inhibitor FPS-ZM1 reduced the migration ability of the C666-1 cells. The numbers of migrated cells in the untreated control, S100P protein and FPS-ZM1 groups were 91.8 $\pm 6.72,200.8 \pm 9.26$ and $30.4 \pm 2.3$, respectively ( $\mathrm{P}<0.001$; Fig. 3D and E).

SIOOP-RAGE activates MAPK and NF- $\kappa B$ signaling. The MAPK signaling pathway is reported to be associated with cell proliferation, differentiation, migration, senescence and apoptosis (20). The activation of NF- $\mathrm{KB}$ is often associated with increased cell survival (21). Therefore, whether extracellular S100P activates these transcription factors was investigated. Consistent with the effects on cell proliferation and migration, blockade of the S100P-RAGE interaction inhibited the effects of S100P on MAPK and NF-kB signaling. Following treatment of the cells with S100P protein, the western blotting results revealed that the p-ERK1/2/ERK1/2, p-p38/p38 and p-MAPK7/MAPK7 ratios and NF-кB1 and p65 expression levels were significantly increased compared with those in the untreated cells $(\mathrm{NF}-\kappa \mathrm{B} 1, \mathrm{P}<0.05$; other proteins, $\mathrm{P}<0.001)$. Conversely, following treatment with the RAGE inhibitor FPS-ZM1, the p-ERK1/2/ERK1/2, p-p38/p38 and p-MAPK7/MAPK7 ratios and NF- $\kappa B 1$ and p65 expression levels were decreased compared with those in the untreated cells (all $\mathrm{P}<0.001$; Fig. 4). These results indicate that the S100P-RAGE interaction activates MAPK and NF- $\kappa B$ signaling in NPC cells.

\section{Discussion}

The gold standard treatment for NPC is radiation therapy, which is a local treatment for the cure or palliative treatment of tumors (22). The cure rate of early-stage NPC is $>90 \%$ (23). However, the efficacy of radiation therapy in advanced stages of NPC is limited owing to radiation resistance (24). Increased tumor volumes, tumor hypoxia and the dysregulation of genes can cause tumor cells to become tolerant to radiation, and thus reduce their sensitivity (25). Therefore, the early diagnosis of NPC and the development of novel treatment approaches are particularly important.

In a previous study, the effect of S100P expression on the proliferation and migration of C666-1 cells was investigated by knocking down S100P expression via infection with S100P small interfering RNA (siRNA) (15). Following S100P knockdown, the downregulation, proliferation and migration of the cells were significantly decreased (15). In addition, it was observed that RAGE expression was downregulated in the cells transfected with S100P siRNA, as compared with the untreated and negative siRNA-transfected controls (15). Notably, certain S100 proteins have been identified to serve 
A
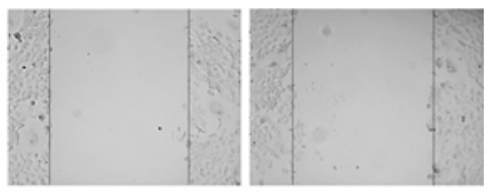

$24 \mathrm{~h}$

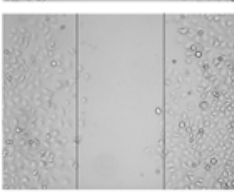

Untreated control

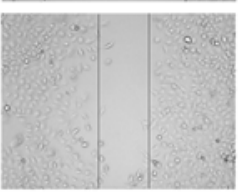

S100P protein

B

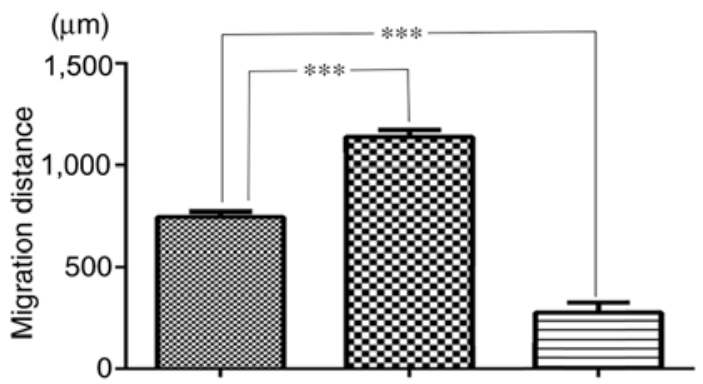

Untreated control S100P protein FPS-ZM1

C
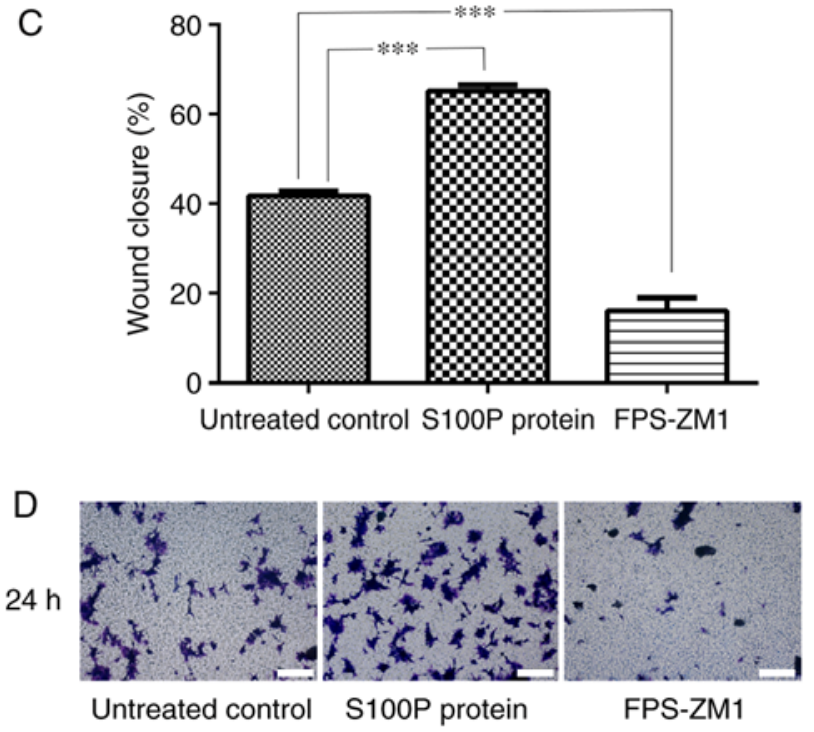

E

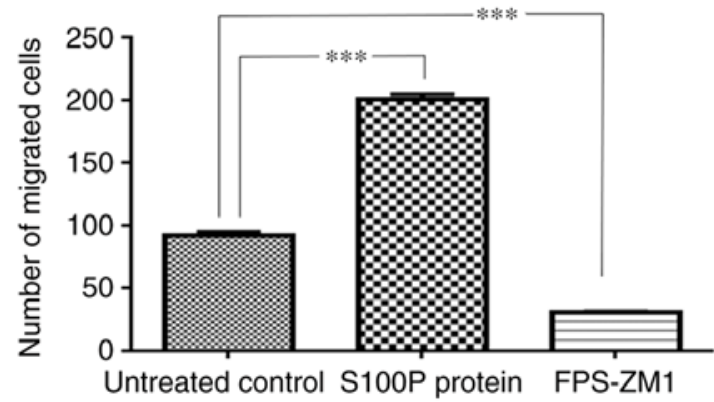

Figure 3. Effects of S100P and RAGE on C666-1 cell migration. (A) Representative images of the wound healing assay (magnification, $\mathrm{x} 400$ ). (B) Measurements of the wound in the cell monolayer revealed that wound closure was induced by treatment with S100P protein and delayed by treatment with the RAGE inhibitor FPS-ZM1 compared with the untreated control. (C) The percentage of wound closure was different in the S100P protein and FPS-ZM1 groups compared with the untreated control group (D) Representative images of the Transwell assay results. Scale bar, $200 \mu \mathrm{m}$. (E) The Transwell assay revealed that the migration ability of C666-1 cells was significantly increased by S100P protein and significantly reduced by the RAGE inhibitor FPS-ZM1. RAGE, receptor for activated glycation end products. ${ }^{* * *} \mathrm{P}<0.001$. a role in tumors by interacting with receptors, suggesting that extracellular S100 proteins have important effects (11). In addition, some S100 proteins have been demonstrated to interact with RAGE in vitro, triggering RAGE-dependent signal transduction in cell-based assays. For example, Arumugam et al (26) demonstrated that S100P triggers the activation of $\mathrm{NF}-\kappa \mathrm{B}$ in a RAGE-dependent manner through a MAPK signaling pathway in BxPC3 and SW480 adenocarcinoma cells. However, the mechanism remains incompletely explored. In the present study, to determine whether the activation of RAGE by $\mathrm{S} 100 \mathrm{P}$ is required for the effects of S100P on the growth and migration of C666-1 cells, the activation of RAGE by S100P was blocked and its effects on cell proliferative and migratory behavior and downstream signaling were investigated. In particular, to elucidate the molecular mechanisms underlying the activity and function of S100P in NPC, the role of S100P as an activator of signaling pathways known to affect the development and progression of numerous types of cancer was assessed. The most frequently reported signaling pathways in which S100P participates include ERK1/2, NF- $\mathrm{B}$ and PI3K/AKT (27). Arumugam et al (26) revealed that exogenous S100P increased the survival of NIH3T3 cells and simultaneously activated ERK in the cells. The MAPK signaling pathway comprises distinct ERK1/2, JNK1/2/3, p38 MAPK and ERK5 pathways (28). The MAPK/ERK pathway is reported to be associated with cell proliferation, differentiation, migration, senescence and apoptosis (20). The present study demonstrated that the S100P-RAGE interaction is associated with MAPK activation in C666-1 cells.

S100P has been reported to exert autocrine effects via RAGE that stimulate cell proliferation and survival via the $\mathrm{NF}-\kappa \mathrm{B}$ pathway (26). The transcription factor $\mathrm{NF}-\kappa \mathrm{B}$ is a nuclear factor that binds to the enhancer element of the immunoglobulin $\kappa$ light-chain of activated B cells (29). The NF- $\kappa$ B transcription factor family has five members, known as p65 (RelA), RelB, c-Rel, NF- $\kappa$ B1 and NF- $\kappa$ B2. The constitutive activation of $\mathrm{NF}-\kappa \mathrm{B}$ has been demonstrated to lead to the promotion of cell proliferation, angiogenesis, invasion and metastasis (21). Consistent with this, the present study detected a significant increase in NF- $\kappa \mathrm{B}$ activation in NPC.

The inhibition of S100P, using antisense mRNA retroviral transfection for example, has been shown to decrease cellular motility and metastatic potential in colon, gastric and breast cancer cell lines (30-32). The expression of S100P has been identified to be associated with the resistance of cancers to several chemotherapeutic agents, and its silencing sensitizes cancer cells to cisplatin and oxaliplatin in vitro $(33,34)$. In the present study, the ability of extracellular S100P to activate MAPK and NF- $\kappa$ B signaling was investigated. Notably, blockade of the S100P-RAGE interaction inhibited the effects of S100P on MAPK and NF- $\mathrm{B}$ signaling, which is similar to its effects on cell proliferation and migration.

The present study has potential limitations, including the relatively small number of clinical samples and the use of only one cell line. However, NPC is associated with multiple risk factors, including EBV infection $(5,6)$, and the C666-1 cell line consistently carries EBV in long-term cultures (16). Therefore, only the C666-1 cell line was used. Further studies using primary cultures of NPC cells and in vivo 
A

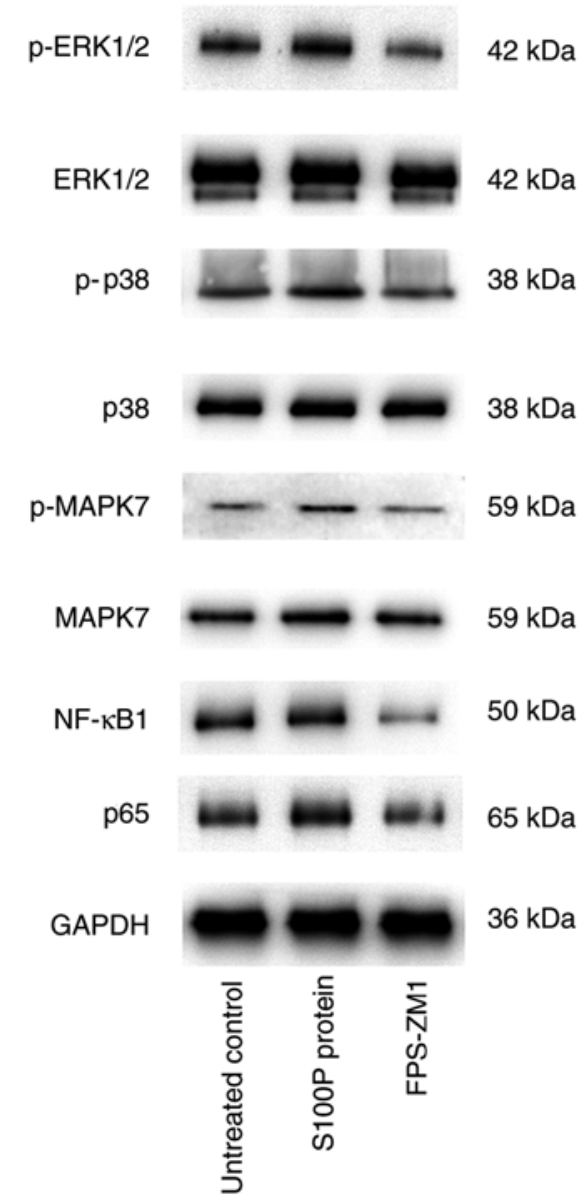

B
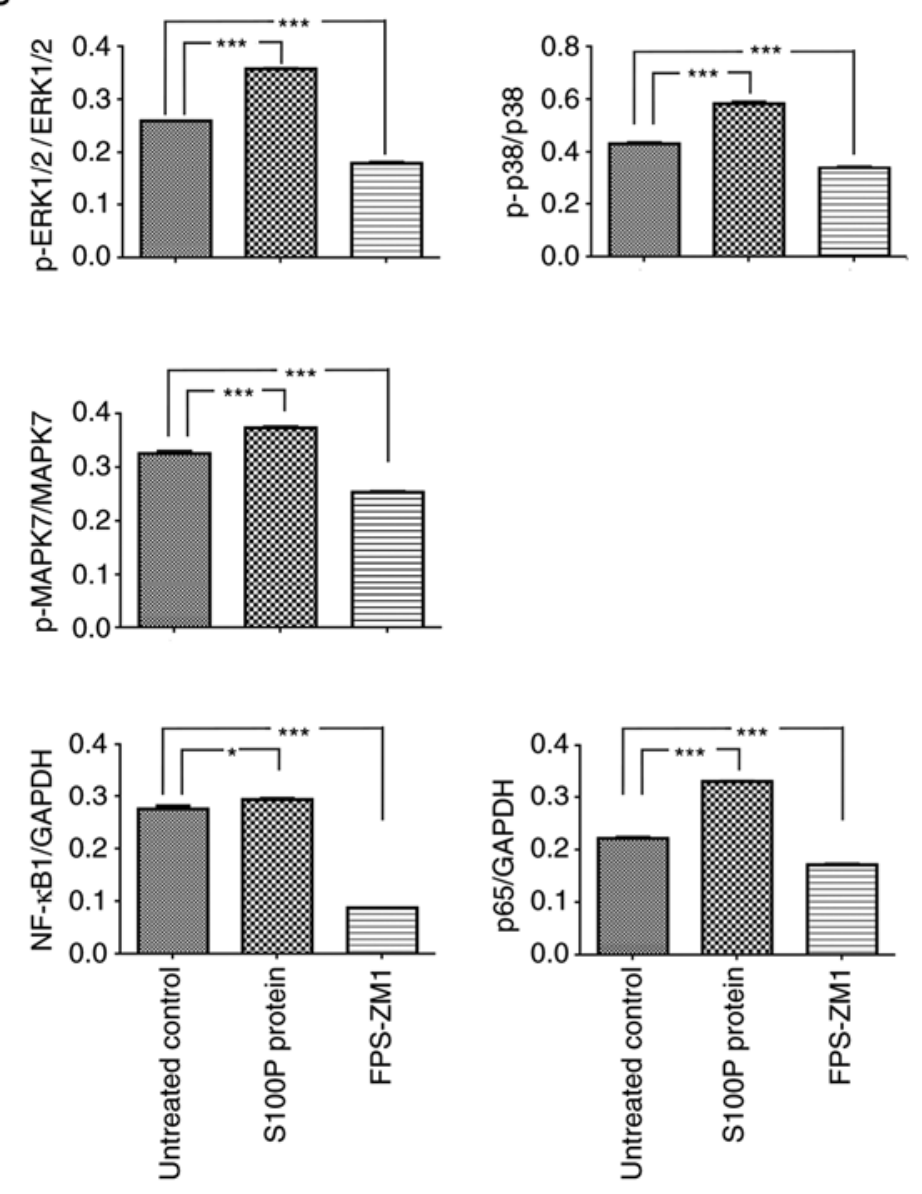

Figure 4. S100P-RAGE activates MAPK and NF- $\mathrm{kB}$ signaling in C666-1 cells. (A) Representative western blots of cells treated with S100P protein or RAGE inhibitor FPS-ZM1. (B) Quantified western blotting data showing that p-ERK1/2/ERK1/2, p-p38/p38 and p-MAPK7/MAPK7 ratios and NF-кB1 and $\mathrm{p} 65$ expression levels were significantly increased in the S100P protein group and significantly reduced in the FPS-ZM1 group compared with those in untreated cells. ${ }^{*} \mathrm{P}<0.05$ and ${ }^{* * * *} \mathrm{P}<0.001$. RAGE, receptor for activated glycation end products; MAPK, mitogen-activated protein kinase; ERK, extracellular signal-related kinase.

experiments are required in the future. Also, although significant data were obtained in the experiments in the present study, the potential of S100P-RAGE blockade as a therapeutic treatment for NPC requires further examination in a larger number of patients.

In conclusion, the present results confirm and extend those of our previous study, and suggest that extracellular S100P may participate in the proliferation and migration of C666-1 cells by binding to RAGE and activating the MAPK and NF- $\kappa B$ signaling pathways. Therefore, blocking S100P-RAGE function might also be expected to improve the response of NPC to therapeutic treatments.

\section{Acknowledgements}

Not applicable.

\section{Funding}

This study was supported by funding from the Jinshan District Science and Technology Innovation project (grant no. 2017-3-07) and the Qihang Plan of Jinshan Hospital of Fudan University (grant no. 2018-JSYYQH-02).

\section{Availability of data and materials}

The datasets used and/or analyzed during the current study are available from the corresponding author on reasonable request.

\section{Authors' contributions}

HJ performed the diagnostic investigations and biopsy treatments. CW performed the experiments and wrote the manuscript. XW and CW confirm the authenticity of all the raw data. XW performed the statistical analysis and analyzed the data. AH performed and guided experiment operations. YW collected and analyzed pathological data. All the authors read and approved the final version of the manuscript.

\section{Ethics approval and consent to participate}

All experimental procedures and protocols were approved by the Ethics Committee of Jinshan Hospital Affiliated to Fudan University (approval no. 2018-05-01). The participants signed informed consent forms for use of their tissues in scientific research. 


\section{Patient consent for publication}

Not applicable.

\section{Competing interests}

The authors declare that they have no competing interests.

\section{References}

1. Tian Y, Tang L, Yi P, Pan Q, Han Y, Shi Y, Rao S, Tan S, Xia L, Lin J, et al: miRNAs in radiotherapy resistance of nasopharyngeal carcinoma. J Cancer 11: 3976-3985, 2020.

2. Chen YP, Chan ATC, Le QT, Blanchard P, Sun Y and Ma J: Nasopharyngeal carcinoma. Lancet 394: 64-80, 2019.

3. Lee AW, Ng WT, Chan YH, Sze H, Chan C and Lam TH: The battle against nasopharyngeal cancer. Radiother Oncol 104: 272-278, 2012

4. Cao SM, Simons MJ and Qian CN: The prevalence and prevention of nasopharyngeal carcinoma in China. Chin J Cancer 30 114-119, 2011.

5. Tu C, Zeng Z, Qi P, Li X, Yu Z, Guo C, Xiong F, Xiang B, Zhou M, Gong Z, et al: Genome-wide analysis of 18 epstein-barr viruses isolated from primary nasopharyngeal carcinoma biopsy specimens. J Virol 91: e00301-e00317, 2017.

6. Lam WKJ and Chan JYK: Recent advances in the management of nasopharyngeal carcinoma. F1000Res 7: F1000, 2018.

7. Nakayama H, Ohuchida K, Yonenaga A, Sagara A, Ando Y, Kibe S, Takesue S, Abe T, Endo S, Koikawa K, et al: S100P regulates the collective invasion of pancreatic cancer cells into the lymphatic endothelial monolayer. Int J Oncol 55: 211-222, 2019.

8. Sasahira T, Kirita T, Bhawal UK, Yamamoto K, Ohmori H, Fujii K and Kuniyasu H: Receptor for advanced glycation end products (RAGE) is important in the prediction of recurrence in human oral squamous cell carcinoma. Histopathology 51: 166-172, 2007.

9. Choi J, Lee MK, Oh KH, Kim YS, Choi HY, Baek SK, Jung KY, Woo JS, Lee SH and Kwon SY: Interaction effect between the receptor for advanced glycation end products (RAGE) and high-mobility group box-1 (HMGB-1) for the migration of a squamous cell carcinoma cell line. Tumori 97: 196-202, 2011.

10. Leclerc E, Fritz G, Vetter SW and Heizmann CW: Binding of S100 proteins to RAGE: An update. Biochim Biophys Acta 1793 993-1007, 2009.

11. Hofmann MA, Drury S, Fu C, Qu W, Taguchi A, Lu Y, Avila C, Kambham N, Bierhaus A, Nawroth P, et al: RAGE mediates a novel proinflammatory axis: A central cell surface receptor for S100/calgranulin polypeptides. Cell 97: 889-901, 1999.

12. Becker T, Gerke V, Kube E and Weber K: S100P, a novel $\mathrm{Ca}(2+)$-binding protein from human placenta. cDNA cloning, recombinant protein expression and $\mathrm{Ca} 2+$ binding properties. Eur J Biochem 207: 541-547, 1992

13. Prica F, Radon T, Cheng Y and Crnogorac-Jurcevic T: The life and works of S100P-from conception to cancer. Am J Cancer Res 6: 562-576, 2016

14. Arumugam T, Simeone DM, Van Golen K and Logsdon CD: S100P promotes pancreatic cancer growth, survival, and invasion. Clin Cancer Res 11: 5356-5364, 2005.

15. Liu Y, Wang C, Shan X, Wu J, Liu H, Liu H, Zhang J, Xu W, Sha Z, $\mathrm{He} \mathrm{J}$ and Fan J: S100P is associated with proliferation migration in nasopharyngeal carcinoma. Oncol Lett 14: 525-532, 2017.
16. Cheung ST, Huang DP, Hui AB, Lo KW, Ko CW, Tsang YS, Wong N, Whitney BM and Lee JC: Nasopharyngeal carcinoma cell line (C666-1) consistently harbouring Epstein-Barr virus. Int J Cancer 83: 121-126, 1999.

17. Hudson BI and Lippman ME: Targeting RAGE signaling in inflammatory disease. Annu Rev Med 69: 349-364, 2018.

18. Mahmood T and Yang PC: Western blot: Technique, theory, and trouble shooting. N Am J Med Sci 4: 429-434, 2012.

19. Franken NA, Rodermond HM, Stap J, Haveman J and van Bree C: Clonogenic assay of cells in vitro. Nat Protoc 1: 2315-2319, 2006.

20. Sun Y, Liu WZ, Liu T, Feng X, Yang N and Zhou HF: Signaling pathway of MAPK/ERK in cell proliferation, differentiation, migration, senescence and apoptosis. J Recept Signal Transduct Res 35: 600-604, 2015.

21. Pramanik KC, Makena MR, Bhowmick K and Pandey MK: Advancement of NF- $\kappa \mathrm{B}$ signaling pathway: A novel target in pancreatic cancer. Int J Mol Sci 19: 3890, 2018.

22. Huang T, Yin L, Wu J, Gu JJ, Wu JZ, Chen D, Yu HL, Ding K, Zhang N, Du MY, et al: MicroRNA-19b-3p regulates nasopharyngeal carcinoma radiosensitivity by targeting TNFAIP3/NF- $\kappa \mathrm{B}$ axis. J Exp Clin Cancer Res 35: 188, 2016.

23. Chan AT: Current treatment of nasopharyngeal carcinoma. Eur J Cancer 47 (Suppl 3): S302-S303, 2011.

24. Yang H, Zhang G, Che X and Yu S: Slug inhibition increases radiosensitivity of nasopharyngeal carcinoma cell line C666-1. Exp Ther Med 15: 3477-3482, 2018.

25. Barker HE, Paget JT, Khan AA and Harrington KJ: The tumour microenvironment after radiotherapy: Mechanisms of resistance and recurrence. Nat Rev Cancer 15: 409-425, 2015.

26. Arumugam T, Simeone DM, Schmidt AM and Logsdon CD S100P stimulates cell proliferation and survival via receptor for activated glycation end products (RAGE). J Biol Chem 279: 5059-5065, 2004.

27. Parkkila S, Pan PW, Ward A, Gibadulinova A, Oveckova I, Pastorekova S, Pastorek J, Martinez AR, Helin HO and Isola J: The calcium-binding protein S100P in normal and malignant human tissues. BMC Clin Pathol 8: 2, 2008.

28. Stecca B and Rovida E: Impact of ERK5 on the hallmarks of cancer. Int J Mol Sci 20: 1426, 2019.

29. Sen R and Baltimore D: Multiple nuclear factors interact with the immunoglobulin enhancer sequences. Cell 46: 705-716, 1986.

30. Jiang L, Lai YK, Zhang J, Wang H, Lin MC, He ML and Kung HF: Targeting S100P inhibits colon cancer growth and metastasis by Lentivirus-mediated RNA interference and proteomic analysis. Mol Med 17: 709-716, 2011.

31. Ning X, Sun S, Hong L, Liang J, Liu L, Han S, Liu Z, Shi Y, Li Y, Gong $\mathrm{W}$, et al: Calcyclin-binding protein inhibits proliferation, tumorigenicity, and invasion of gastric cancer. Mol Cancer Res 5: 1254-1262, 2007.

32. Beissel B, Silva ID, Pesquero JB, Russo J, Schor N and Bellini MH: S-phase reduction in T47D human breast cancer epithelial cells induced by an S100P antisense-retroviral construct. Oncol Rep 17: 611-615, 2007.

33. Zhang YW, Zheng Y, Wang JZ, Lu XX, Wang Z, Chen LB, Guan XX and Tong JD: Integrated analysis of DNA methylation and mRNA expression profiling reveals candidate genes associated with cisplatin resistance in non-small cell lung cancer. Epigenetics 9: 896-909, 2014.

34. Tang H, Liu YJ, Liu M and Li X: Establishment and gene analysis of an oxaliplatin-resistant colon cancer cell line THC8307/ L-OHP. Anticancer Drugs 18: 633-639, 2007.

This work is licensed under a Creative Commons Attribution-NonCommercial-NoDerivatives 4.0 International (CC BY-NC-ND 4.0) License. 